\title{
Effects of continuous positive airway pressure on exhaled transforming growth factor- $\beta$ and vascular endothelial growth factor in patients with obstructive sleep apnea
}

\author{
Ching-Chi Lin ${ }^{1}$, Shwu-Fang Liaw ${ }^{2}$, Chung-Hsin Chiu ${ }^{3}$, Mei-Wei Lin ${ }^{1}$ \\ ${ }^{1}$ Division of Pulmonary Medicine, Department of Internal Medicine, Taipei Tzu Chi Hospital, Buddhist Tzu Chi Medical Foundation, New Taipei \\ City; ${ }^{2}$ Department of Medical Research, Mackay Memorial Hospital, Taipei; ${ }^{3}$ Sleep Center, Mackay Memorial Hospital, Taipei \\ Contributions: (I) Conception and design: CC Lin; (II) Administrative support: SF Liaw, CH Chiu; (III) Provision of study materials or patients: CC \\ Lin, CH Chiu; (IV) Collection and assembly of data: SF Liaw, CH Chiu, MW Lin; (V) Data analysis and interpretation: CC Lin, SF Liaw, CH Chiu; \\ (VI) Manuscript writing: All authors; (VII) Final approval of manuscript: All authors. \\ Correspondence to: Ching-Chi Lin. Division of Pulmonary Medicine, Department of Internal Medicine, Taipei Tzu Chi Hospital, Buddhist Tzu Chi \\ Medical Foundation, New Taipei City 23142. Email: cclinpro@yahoo.com.
}

Background: Both transforming growth factor $\beta$ (TGF- $\beta$ ) and vascular endothelial growth factor (VEGF)
are master regulators of airway remodeling; however, their pathological roles in obstructive sleep apnea (OSA)
remain unclear. The aim of the present study was to evaluate the expression of TGF- $\beta$ and VEGF protein in
the serum and exhaled breath condensate (EBC) before and after continuous positive airway pressure (CPAP)
treatment in OSA patients.

Methods: Forty patients with moderate to severe OSA requiring CPAP and 20 healthy subjects were prospectively recruited. The concentrations of TGF- $\beta$ and VEGF protein in the serum and EBC were evaluated by enzyme-linked immunosorbent assay. All OSA patients underwent a sleep study that was repeated 3 months after receiving CPAP therapy.

Results: Protein concentrations of TGF- $\beta$ and VEGF in the serum did not differ between healthy controls and OSA patients before CPAP treatment. There was also no difference in the serum protein concentrations of TGF- $\beta$ and VEGF of the OSA patients before and after CPAP treatment. However, both the TGF- $\beta$ and VEGF protein concentrations in the EBC were higher in the OSA patients than those in control subjects, and recovered to normal levels after CPAP.

Conclusions: Successful treatment of OSA by CPAP can restore the TGF- $\beta$ and VEGF protein concentrations in the EBC.

Keywords: Transforming growth factor $\beta$ (TGF- $\beta$ ); vascular endothelial growth factor (VEGF); airway remodeling; obstructive sleep apnea (OSA); exhaled breath condensate (EBC); continuous positive airway pressure (CPAP)

Submitted May 20, 2019. Accepted for publication Dec 04, 2019.

doi: $10.21037 /$ jtd.2019.12.55

View this article at: http://dx.doi.org/10.21037/jtd.2019.12.55

\section{Introduction}

Severe obstructive sleep apnea (OSA) is characterized by repeated upper airway obstructions (1), intermittent hypoxia, increase sympathetic tone and a significant reduction in rapid eye movement (REM) sleep (1). Previous studies have also shown that oxidative stress is increased in the upper airways of OSA patients (2-4). Many pathological mechanisms have been postulated for the airway oxidative stress and inflammation in OSA, including hypoxemia and reoxygenation-induced ischemia-reperfusion injury caused by repeated obstructive reopening during sleep, repeated trauma secondary to recurring episodes of obstructive 
apnea, adipose tissue serving as a reservoir of cytokines, and leptin-mediated systemic inflammation (2-4).

Transforming growth factor $\beta$ (TGF- $\beta$ ) is a multifunctional growth factor, a master regulator of immune responses and a powerful anti-inflammatory factor. TGF- $\beta$ are synthesized mainly from epithelial cells, myofibroblasts and inflammatory cells. TGF- $\beta$ regulates inflammation, as well as anti-inflammation, and activate fibroblasts to synthesize extracellular matrix proteins involved in fibrosis, tissue repair and remodeling. In addition, TGF- $\beta$ inhibits the production of matrix metalloproteinases (MMPs, matrixdegrading enzymes), and promotes the production of tissue inhibitors of metalloproteinases (TIMPs). TGF- $\beta$ has also been recognized as a 'master switch' in the induction of the epithelial-mesenchymal transition, involving the conversion of differentiated epithelial cells into fibroblasts. This results in collagen deposition and thickening of the affected tissue $(5-7)$.

Vascular endothelial growth factor (VEGF) is an angiogenic factor. VEGF induces angiogenesis by promoting the proliferation and differentiation of endothelial cells; increasing the number, size, and area of blood vessels; and increasing vascular permeability (8). VEGF also upregulates Th2-type inflammatory reactions and chemotaxis for monocytes and eosinophils, and enhances allergic inflammation $(9,10)$. VEGF can also promote the proliferation of airway smooth muscle cells $(9,10)$. Under hypoxic conditions, VEGF expression is stimulated to allow new blood vessels to grow and bring in more oxygen. But VEGF also plays a crucial role in cancer growth. Cancer cells express VEGF to induce angiogenesis in order to grow and metastasize. Most tumors show higher levels of VEGF (11).

There is ample evidence showing that upper airway inflammation causes changes in the airway structure in OSA patients (2-4). However, direct analysis of the upper airway by means of biopsy is invasive and difficult. As an alternative, airway oxidative stress and inflammation are generally detected by examination of the exhaled breath condensate (EBC), representing a simple and non-invasive technique for many respiratory diseases (2).

Although continuous positive airway pressure (CPAP) has proven to be very effective in the treatment of patients with moderate or severe OSA (12), to the best of our knowledge, the effect of CPAP treatment on the levels of TGF- $\beta$ and VEGF protein in the EBC of OSA patients has not been evaluated to date. Therefore, we determined the baseline EBC levels of TGF- $\beta$ and VEGF in patients with
OSA and healthy controls, and explored their relationship with the severity of OSA and the changes after 3 months of CPAP treatment.

\section{Methods}

\section{Selection of subjects and study protocol}

Patients visiting the sleep laboratory of our hospital for sleep studies were considered for enrollment in the study. They came either by referral from a physician who determined that they had a clinical problem meriting overnight sleep polysomnographic evaluation or by their own request. From March 2014 to January 2016, a total of 868 overnight sleep studies were performed in our sleep laboratory. A total of 387 patients had moderately severe or severe OSA (as defined below); of these 125 patients who were newly diagnosed with moderately severe to severe OSA — proven by overnight sleep study — and can tolerate CPAP treatment and desired CPAP treatment for at least 3 months, and who had not yet started CPAP treatment were prospectively recruited for this study. Seventy-nine patients were ineligible for the study because of one or more of the exclusion criteria, 5 declined to participate, and 1 was lost during follow up; this left 40 patients who were enrolled in the study. During the same period, 38 healthy individuals who were snorers referred to the sleep disorder center, who were found after polysomnography to have an apnea-hypopnea index (AHI) of less than 5 and were not hypersomnolent, were recruited as control group; of these, 13 were excluded because of one or more exclusion criteria and 5 declined to participate, leaving 20 patients, who agreed to serve as control group. Patients aged $>65$ years, smokers (>10 pack-years), and with diabetes mellitus (fasting blood glucose $>120 \mathrm{mg} / \mathrm{dL}$ or postprandial blood glucose $>200 \mathrm{mg} / \mathrm{dL}$ ), moderate or severe dyslipidemia (cholesterol >230 mg/dL or triglycerides >250 mg/dL), hypertension (two separate measurements of blood pressure $>140 / 85$ ), heart disease, and recent acute infection were excluded from the study. The control group included 20 healthy people without OSA (AHI $<5$ events/h plus absence of daytime sleepiness). To match subjects in the two groups for body weight, only individuals with a body mass index $(\mathrm{BMI})>25\left(\mathrm{~kg} / \mathrm{m}^{2}\right)$ were included in the control group, and the OSA group included only subjects with a $\mathrm{BMI}<32$. This study was approved by the Ethics Review Committees of our hospital (approval number: 04-XD39-106) and all participants provided written informed consent. 
All participants in this study were evaluated based on a medical history interview, physical examination, and blood tests (including hematocrit, pre-and post-prandial blood glucose, cholesterol, and triglycerides). All subjects received a pulmonary function test and a full-night polysomnography examination. After resting for at least $15 \mathrm{~min}$ in the sleep lab, blood pressure was measured at $7 \mathrm{am}, 8 \mathrm{pm}$, and $10 \mathrm{pm}$. Peripheral blood and EBC samples were collected for TGF- $\beta$ and VEGF protein level analysis at 7 am after the full-night polysomnography examination. In the OSA group, these examinations were repeated 3 months after CPAP treatment.

\section{Sleep study}

All participants underwent a full-night polysomnography examination at the sleep laboratory of our hospital using the Embla N7000 system (Embla, Woodbridge, UK). Sleep scores and respiratory events were manually calculated according to previously defined standard criteria (13). In brief, apnea was defined as an airflow amplitude (determined by an oronasal thermal sensor) less than $10 \%$ the baseline amplitude during apnea. The amplitude criteria for apnea were an event lasting at least $10 \mathrm{~s}$ and the amplitude criteria were met for at least $9 \mathrm{~s}$ of the event's duration. Hypopnea was defined as a $\geq 50 \%$ reduction in one of three respiratory signals: airflow signal (detected by a nasal air pressure transducer) or either respiratory or abdominal signals of respiratory inductance plethysmography for more than $10 \mathrm{~s}$ associated with an oxygen desaturation of $\geq 3 \%$ or an arousal (12). At least $90 \%$ of the event duration had to meet the amplitude criteria. The AHI was defined as the mean number of the sum of episodes of apneas and hypopneas per hour of sleep. Oxygen desaturation index (ODI) was defined as the mean number of $\mathrm{SpO}_{2}$ drops $\geq 3 \%$ per hour of total sleep time (TST) (number/h). The arousal index (AI) was defined as the mean number of arousals per hour of sleep, while sleep efficiency was calculated as the percentage of TST divided by the total time in bed (13). OSA was defined as an AHI score $\geq 5$, and an AHI score $\geq 20$ was considered to indicate moderate or severe OSA. Central apneadefined as the cessation of airflow at the nose and mouth (oronasal thermal sensor signal) for a period $\geq 10 \mathrm{~s}$ in the absence of any effort-is identified either through the chest or abdomen respiratory inductance plethysmography signal and via the absence of flattening of the inspiratory portion of the nasal pressure.

\section{Hypersomnolence}

Daytime hypersomnolence was assessed by using the Epworth sleepiness scale (ESS). Scores range from 0 (least likely) to 24 (most likely). A score of 11 or higher is defined to be an abnormal degree of daytime hypersomnolence (14).

\section{Collection of EBC and measurement of TGF- $\beta$ and VEGF protein concentrations in the serum and EBC}

EBC samples were collected using a TURBO-DECCS apparatus (Medivac, Parma, Italy) at a fixed collection temperature of $-5{ }^{\circ} \mathrm{C}$. Subjects were requested to breathe into the collection system for 15-30 min under normal tidal volume conditions, and the EBC $(2-3 \mathrm{~mL})$ was collected in disposable tubes. These solutions were stored at $-80{ }^{\circ} \mathrm{C}$ immediately until the assay.

A $3 \mathrm{~mL}$ peripheral blood sample was collected in EDTA tubes and set aside for 15-30 min. The clot was then removed by centrifuging at $1,500 \times \mathrm{g}$ for $10 \mathrm{~min}$ in a refrigerated centrifuge. The liquid component (serum) was immediately transferred into a clean polypropylene tube using a Pasteur pipette. The samples were maintained at $2-8{ }^{\circ} \mathrm{C}$ while handling.

The TGF- $\beta$ and VEGF protein levels in the serum and $\mathrm{EBC}$ were determined by enzyme-linked immunosorbent assay (ELISA) with Human TGF- $\beta$ and VEGF Instant ELISA kits (eBioscience, San Diego, CA, USA).

\section{Pre-post CPAP change of TGF- $\beta$ and VEGF protein concentrations in the EBC, AHI, and minimum arterial oxybemoglobin saturation $\left(\mathrm{SaO}_{2}\right)$}

The degree of improvement in TGF- $\beta$ and VEGF protein concentrations in the $\mathrm{EBC}$, along with the AHI and minimum $\mathrm{SaO}_{2}$ were calculated by subtracting the values obtained before CPAP treatment from those obtained after the treatment.

\section{Data analysis}

Student's $t$-test was used for comparisons between the control and OSA groups before CPAP treatment and a paired $t$-test was applied for comparisons before and after CPAP treatment within the OSA group. All values are expressed as the mean \pm standard deviation. Significance was defined at $\mathrm{P}<0.05$. For controlling potential confounding 
variables including age, gender, and $\mathrm{BMI}$, we used partial correlation to evaluate linear relationship between variables. Simple linear regression was used to evaluate the correlations between TGF- $\beta$ and VEGF protein levels in the EBC with AHI and minimum $\mathrm{SaO}_{2}$.

\section{Results}

\section{Subject characteristics}

The basic characteristics and lung function test results did not differ between the patient and control subjects at baseline, or in the 3-month interval before CPAP treatment (Table 1). There were no significant differences in the BMI, systolic and diastolic blood pressure, and triglyceride and cholesterol levels before and after 3 months of CPAP treatment. The OSA group had an abnormal sleep architecture and breathing parameters before CPAP treatment when compared to those of the control subjects (Table 2). After CPAP treatment, in addition to the percentage of stage 2 sleep, the OSA patients showed significant improvement in all sleep and respiratory parameters (Table 2). There were no significant differences in the TST between the patient and control subjects at baseline and between before and after 3 months of CPAP treatment.

\section{TGF- $\beta$ and VEGF protein levels in the serum and EBC}

The serum concentrations of TGF- $\beta$ and VEGF protein did not differ between the OSA and control groups before CPAP treatment. There was also no difference in the serum concentrations of TGF- $\beta$ and VEGF in the OSA group before and after CPAP treatment (Figure 1A,B). In contrast, the OSA group had significantly higher TGF- $\beta$ and VEGF protein concentrations in the EBC before CPAP treatment than those of the control group $(\mathrm{P}<0.05)$, which recovered to normal levels after 3 months of CPAP treatment $(\mathrm{P}<0.05$; Figure $1 C, D)$.

\section{Relationships between TGF- $\beta$ and VEGF protein concentrations in the EBC with AHI and minimum $\mathrm{SaO}_{2}$}

TGF- $\beta$ protein levels in the EBC were positively correlated with AHI $(\mathrm{R}=0.44, \mathrm{P}<0.05$; Figure $2 A)$ and VEGF protein levels in the $\mathrm{EBC}(\mathrm{R}=0.41, \mathrm{P}<0.05$; Figure $2 B)$, but negatively correlated with minimum $\mathrm{SaO}_{2}(\mathrm{R}=-0.45$, $\mathrm{P}<0.05)$ before CPAP treatment in OSA patients. Similarly,
VEGF protein levels in the EBC were positively correlated with AHI $(\mathrm{R}=0.41, \mathrm{P}<0.05$; Figure $2 C)$ and negatively correlated with minimum $\mathrm{SaO}_{2}(\mathrm{R}=-0.49, \mathrm{P}<0.05)$ before the CPAP treatment in OSA patients. After controlling age, gender, and $\mathrm{BMI}$, the results of partial correlation between TGF- $\beta$ and VEGF protein concentrations in the EBC with AHI and minimum $\mathrm{SaO}_{2}$ were similarly significant.

Relationships between pre-post changes of TGF- $\beta$ and $V E G F$ protein levels in the EBC with pre-post changes of AHI and minimum $\mathrm{SaO}_{2}$

The pre-post changes of TGF- $\beta$ protein levels in the EBC positively correlated with the pre-post changes of AHI $(\mathrm{R}=0.44, \mathrm{P}<0.05$; Figure $3 A)$ and VEGF protein concentrations in the $\mathrm{EBC}(\mathrm{R}=0.47, \mathrm{P}<0.05$; Figure $3 B)$, and negatively correlated with the pre-post changes of minimum $\mathrm{SaO}_{2}(\mathrm{R}=-0.42, \mathrm{P}<0.05)$ after CPAP treatment. The prepost changes of EBC VEGF protein concentrations were positively correlated with the pre-post changes of AHI $(\mathrm{R}=0.41, \mathrm{P}<0.05$; Figure $3 C)$ and negatively correlated with the pre-post changes of minimum $\mathrm{SaO}_{2}(\mathrm{R}=-0.47, \mathrm{P}<0.05)$. After controlling age, gender, and BMI, the results of partial correlation between pre-post changes of TGF- $\beta$ and VEGF protein levels in the EBC with pre-post changes of $\mathrm{AHI}$ and minimum $\mathrm{SaO}_{2}$ were similarly significant.

\section{Relationship between the 3-month mean duration/night of CPAP treatment and the pre-post changes in the TGF- $\beta$ and VEGF levels in the EBC}

The 3-month mean duration/night of CPAP treatment was $403.2 \pm 71.0 \mathrm{~min}$ for the OSA group. After CPAP treatment, the 3-month mean duration/night of CPAP treatment were negatively correlated with pre-post changes in TGF- $\beta$ $(\mathrm{R}=-0.43, \mathrm{P}<0.05$; Figure $4 A)$ and VEGF protein in EBC $(\mathrm{R}=-0.44, \mathrm{P}<0.05$; Figure $4 B)$. After controlling for age, sex, and BMI, the results of partial correlation between pre-post changes in TGF- $\beta$ and VEGF protein levels in the EBC with the 3-month mean duration/night of CPAP treatment showed similar significance.

\section{Discussion}

In this study, we found that the serum concentrations of TGF- $\beta$ and VEGF had no difference between normal subjects and OSA subjects before CPAP treatment. The serum concentrations of TGF- $\beta$ and VEGF in the OSA 
Table 1 Characteristics and pulmonary function tests results before and after CPAP treatment

\begin{tabular}{lccc}
\hline & & & OSA group $(\mathrm{n}=40)$ \\
Characteristics & Control $(\mathrm{n}=20)$ & Before CPAP & After CPAP \\
\cline { 2 - 3 } Age, years & $47 \pm 9$ & $49 \pm 10$ & - \\
Sex (male/female) & $17 / 3$ & $33 / 7$ & $126.4 \pm 5.0$ \\
Systolic pressure, $\mathrm{mmHg}$ & $123.7 \pm 8.1$ & $126.9 \pm 5.9$ & $74.5 \pm 4.9$ \\
Diastolic pressure, $\mathrm{mmHg}$ & $73.3 \pm 6.7$ & $27.7 \pm 1.8$ & $27.3 \pm 1.9$ \\
BMI, kg/m ${ }^{2}$ & $27.1 \pm 1.7$ & $91.9 \pm 6.3$ & $91.6 \pm 7.0$ \\
FVC, \% predicted & $89.2 \pm 6.9$ & $78.8 \pm 3.1$ & $79.0 \pm 3.7$ \\
FEV1/FVC & $78.4 \pm 3.5$ & $43.8 \pm 2.8$ & $44.2 \pm 2.0$ \\
Hematocrit & $43.8 \pm 2.3$ & $199.1 \pm 25.0$ & $197.4 \pm 24.4$ \\
Cholesterol, $\mathrm{mg} / \mathrm{dL}$ & $202.3 \pm 19.3$ & $213.0 \pm 29.3$ & $210.1 \pm 33.3$ \\
Triglyceride, $\mathrm{mg} / \mathrm{dL}$ & $209.2 \pm 25.4$ & & 74.7 \\
\hline
\end{tabular}

Student's $t$-test was applied for comparison between control and OSA group before CPAP and paired $t$-test was used for comparison between before and after CPAP treatment within OSA group. CPAP, continuous positive airway pressure; OSA, obstructive sleep apnea; $\mathrm{BMI}$, body mass index; FVC, forced vital capacity; FEV1, forced expiratory volume in 1 second.

Table 2 Results of sleep study before and after CPAP treatment

\begin{tabular}{|c|c|c|c|}
\hline \multirow{2}{*}{ Variables } & \multirow{2}{*}{ Control $(n=20)$} & \multicolumn{2}{|c|}{ OSA group $(n=40)$} \\
\hline & & Before CPAP & After CPAP \\
\hline AHI, times/hour & $3.7 \pm 1.2$ & $55.7 \pm 16.5^{\star}$ & $3.7 \pm 2.5$ \\
\hline ODI, times/hour & $2.8 \pm 1.2$ & $49.5 \pm 15.8^{*}$ & $2.7 \pm 2.0$ \\
\hline Baseline $\mathrm{SaO}_{2}, \%$ & $98.2 \pm 0.8$ & $97.0 \pm 0.9^{\star}$ & $97.9 \pm 0.7$ \\
\hline Minimum $\mathrm{SaO}_{2}, \%$ & $90.7 \pm 1.9$ & $73.1 \pm 8.0^{*}$ & $90.9 \pm 2.0$ \\
\hline \multicolumn{4}{|l|}{ Sleep architecture, \% } \\
\hline Stage 1 & $13.5 \pm 4.1$ & $28.2 \pm 7.1^{*}$ & $16 \pm 3.1$ \\
\hline Stage 2 & $50.2 \pm 4.3$ & $50.8 \pm 6.3$ & $49.3 \pm 3.9$ \\
\hline Stage 3 & $18.0 \pm 3.0$ & $10.2 \pm 3.4^{*}$ & $17.1 \pm 3.3$ \\
\hline REM & $18.3 \pm 4.0$ & $10.8 \pm 3.6^{\star}$ & $17.6 \pm 3.2$ \\
\hline TST, min & $420.9 \pm 34.9$ & $397.4 \pm 38.1$ & $415.1 \pm 33.6$ \\
\hline Sleep efficiency, \% & $85.9 \pm 6.3$ & $76.4 \pm 6.7^{\star}$ & $88.7 \pm 4.0$ \\
\hline Al, times/hour & $5.1 \pm 0.8$ & $59.5 \pm 22.0^{*}$ & $4.1 \pm 3.7$ \\
\hline
\end{tabular}

Student's $t$-test was applied for comparison between control and OSA group before CPAP and paired $t$-test was used for comparison between before and after CPAP treatment within OSA group. *, $\mathrm{P}<0.05$, for difference before and after CPAP. CPAP, continuous positive airway pressure; OSA, obstructive sleep apnea; $\mathrm{AHI}$, apnea-hypopnea index; ODI, oxygen desaturation index; $\mathrm{SaO}_{2}$, arterial oxyhemoglobin saturation; REM, rapid eye movement; TST, total sleep time; Al, arousal index. 
A

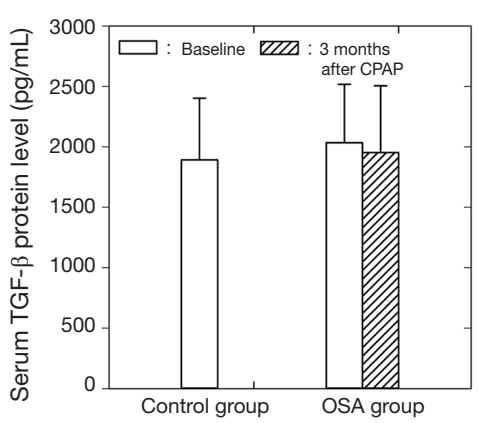

B

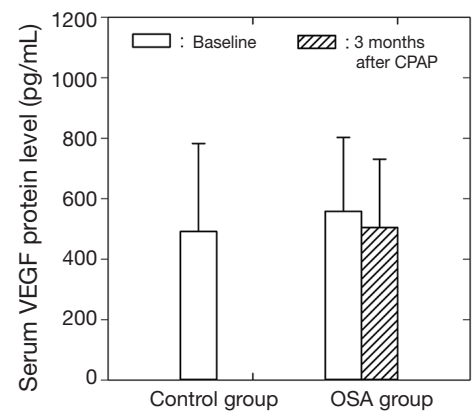

C

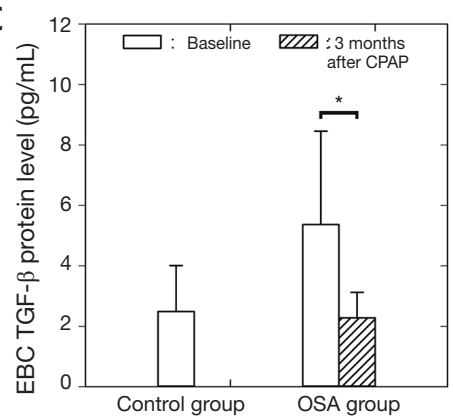

$\mathrm{D}$

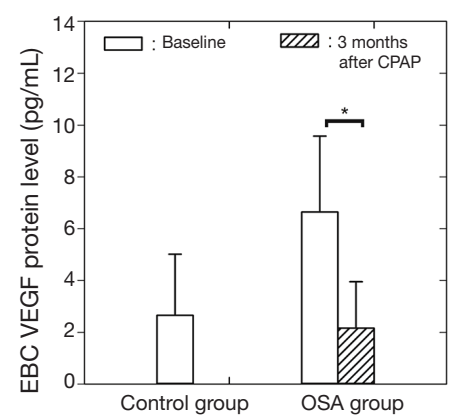

Figure 1 TGF- $\beta$ and VEGF protein levels in the serum and EBC. (A) Serum levels of TGF- $\beta$ between healthy subjects and OSA patients, and before and after CPAP treatment in OSA patients; (B) serum levels of VEGF between healthy subjects and OSA patients, and before and after CPAP treatment in OSA patients; (C) TGF- $\beta$ protein levels in the EBC in patients with OSA before and after CPAP treatment; (D) VEGF protein levels in the EBC in patients with OSA before and after CPAP treatment. *, significantly different from CPAP treatment $(\mathrm{P}<0.05)$. TGF- $\beta$, transforming growth factor $\beta$; OSA, obstructive sleep apnea; CPAP, continuous positive airway pressure; VEGF, vascular endothelial growth factor; EBC, exhaled breath condensate.

subjects had no difference between before and after CPAP treatment. In contrast, the concentrations of TGF- $\beta$ and VEGF in EBC in the subjects with OSA before CPAP treatment were higher than those of the normal controls. These levels returned to normal after CPAP treatment.

Previous studies showed that there was no direct evidence of increased oxidative stress in patients experiencing a short-term return of their moderate-to-severe OSA $(15,16)$. The effect of systemic hypoxia on the circulating levels of TGF- $\beta$ and VEGF, and the correlation between the serum concentrations of TGF- $\beta$ and VEGF with OSA severity remain controversial (17-22). Some studies reported no significant differences between OSA and control subjects (17-20), and short-term CPAP had no impact on the serum concentrations of TGF- $\beta$ and VEGF (19-20). By contrast, other studies reported that serum TGF- $\beta$ and VEGF concentrations were significantly higher in OSA patients than in control subjects and were decreased after CPAP treatment $(21,22)$. In this study, we found no difference in the serum concentrations of TGF- $\beta$ and VEGF between healthy control subjects and OSA patients before CPAP treatment. There were also no differences in these levels in the serum of OSA patients before and after CPAP treatment.

A previous study demonstrated that OSA patients had significantly increased infiltration of inflammatory cells (mainly $\mathrm{T}$ lymphocytes) in the mucosa layer, along with significant structural changes of the upper airway epithelial layer, and differences in the expression pattern of cytokeratin (3). Another study showed a significant increase in the expressions of cytokines in the upper airway epithelial layer in patients with severe OSA (4). Moreover, the OSA patients were reported to show higher numbers of neutrophils in induced sputum and higher levels of exhaled breath markers (such as nitric oxide, carbon monoxide, pentane, hydrogen peroxide, homocysteine, 8-isoprostane, IL-6, IL-8, and leukotriene B4) in EBC. The $\mathrm{pH}$ of the $\mathrm{EBC}$ was also lower in patients with OSA compared to that of the control group (3,23-25). Moreover, the neutrophil cellularity in induced sputum and levels of markers in the 

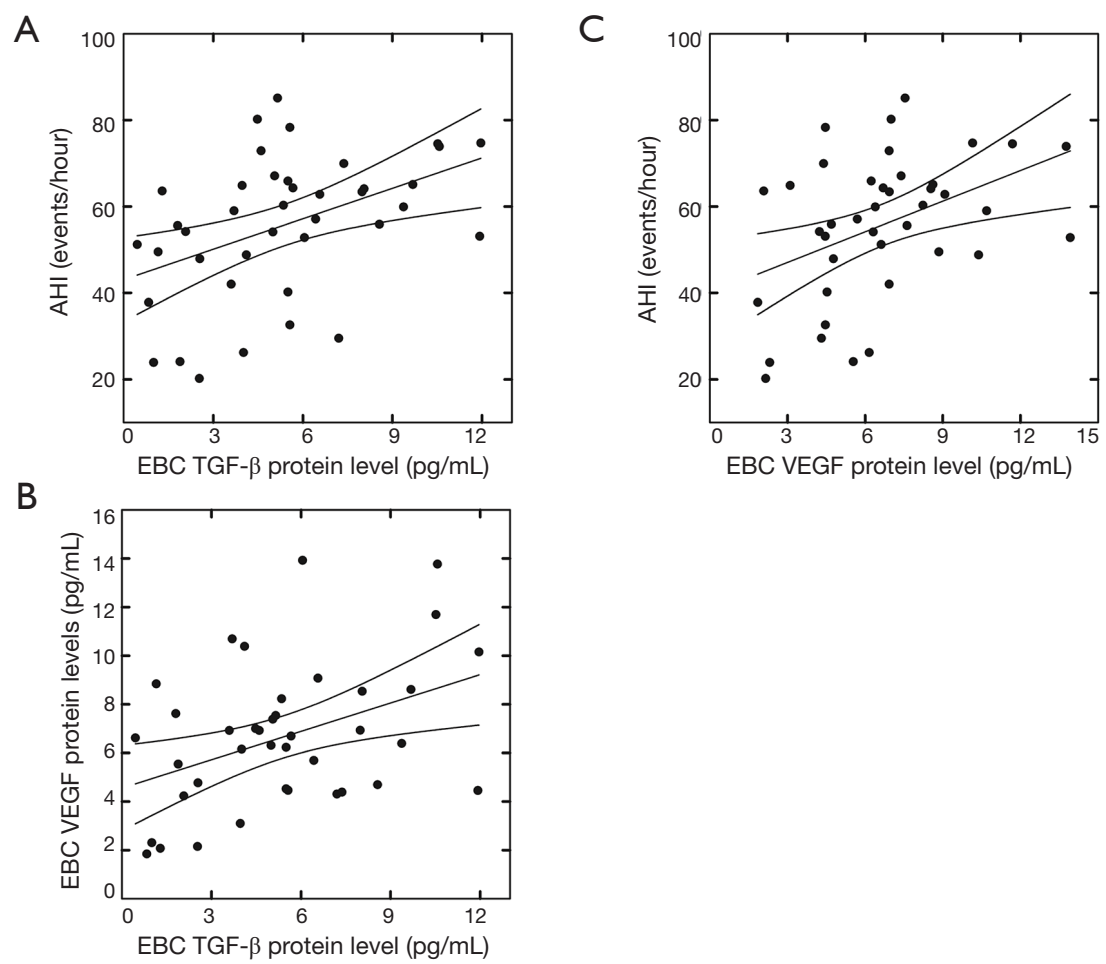

Figure 2 Relationships between AHI and TGF- $\beta$, VEGF protein levels in the EBC. (A) Correlation of TGF- $\beta$ protein concentrations in the EBC with $\mathrm{AHI}$ and (B) VEGF protein concentrations in the EBC in the OSA patients before CPAP treatment; (C) correlation of VEGF protein concentrations in the EBC with $\mathrm{AHI}$ in the OSA patients before CPAP treatment. TGF- $\beta$, transforming growth factor $\beta$; EBC, exhaled breath condensate; AHI, apnea-hypopnea index; VEGF, vascular endothelial growth factor; OSA, obstructive sleep apnea; CPAP, continuous positive airway pressure.

EBC were positively correlated with the severity of OSA, but improved after CPAP treatment (23-24).

Chronic airway disease is a combination of chronic airway inflammation and airway remodeling. Both TGF- $\beta$ and VEGF are master regulators of airway remodeling. Greulich et al. (26) found that the concentrations of extracellular remodeling markers (MMP9/TIMP1 ratio) in pharyngeal washings were significantly higher in OSA patients than those in healthy controls. Ding et al. (27) showed ultrastructure changes characterized by lamellar body degeneration, mitochondrial swelling, and remodeling around the peribonchial and perivascular space in the lungs of a canine OSA model, which were driven by TGF- $\beta / \mathrm{miR}$ 185/CoLA1 signaling. Chronic intermittent hypoxia was found to activate the TGF- $\beta / \mathrm{SMAD} 2 / 3$ pathway, thereby increasing the levels of collagen I, collagen III, and the ratio of MMP2/TIMP2 mRNA, inducing left ventricular fibrosis (28). Wåhlin-Larsson et al. (29) reported higher expression levels of VEGF in the skeletal muscle of patients with sleep disorders.
Intermittent hypoxia, increased oxidative stress, increased sympathetic activity may interfere the balance of metabolic interactions between gut microbiota and the host in OSA leading to an accumulation of significant compounds in blood and hence increased levels of these compounds in breath in OSA. Schwarz et al. (30) found that CPAP withdrawal led to a recurrence of OSA which was accompanied by a significant change in exhaled molecular breath profile. The essential compounds identified in exhaled molecular breath profile are a family of aldehydes, a series of furans phenolic compounds and sulphur-containing compounds. The most significant compounds identified belong to the closely related family of Peroxide molecules (e.g., aldehydes) which implies increased oxidative stress in OSA. As oxidative stress can lead to chronic inflammation by activating a variety of factors such as TGF- $\beta$ and VEGF, it is expected that these factors will be elevated in OSA patients. In this study, we found that the concentrations of TGF- $\beta$ and VEGF in the EBC of patients with OSA were higher before CPAP treatment than those of the control group, and returned 

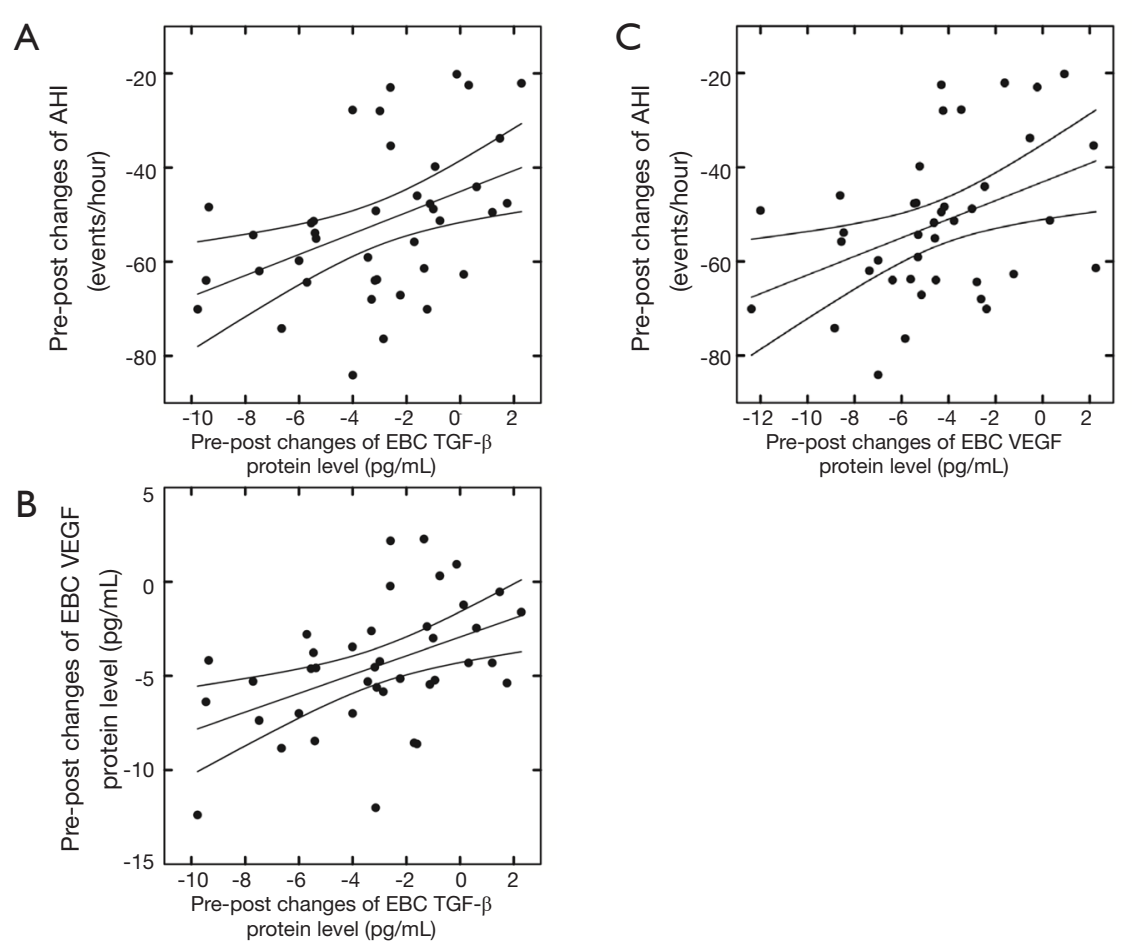

Figure 3 Pre-post changes of TGF- $\beta$ protein levels in the EBC and their correlations with those of (A) AHI and (B) VEGF protein concentrations in the EBC in OSA patients after CPAP treatment; (C) Pre-post changes of VEGF protein levels in EBC and their correlation with those of AHI in OSA patients after CPAP treatment. TGF- $\beta$, transforming growth factor $\beta$; EBC, exhaled breath condensate; AHI, apnea-hypopnea index; VEGF, vascular endothelial growth factor; OSA, obstructive sleep apnea; CPAP, continuous positive airway pressure.
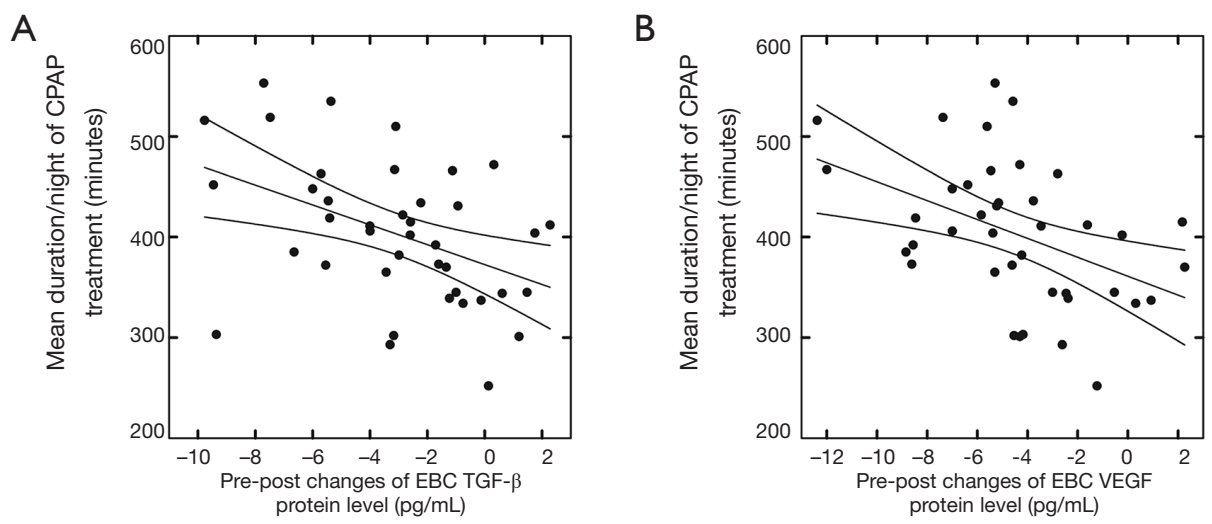

Figure 4 After CPAP treatment, 3-month mean duration/night of CPAP treatment were negatively correlated with pre-post changes in TGF- $\beta(\mathrm{R}=-0.43, \mathrm{P}<0.05$; Figure $4 A)$ and VEGF protein levels in $\mathrm{EBC}(\mathrm{R}=-0.44, \mathrm{P}<0.05$; Figure $4 B)$. CPAP, continuous positive airway pressure; TGF- $\beta$, transforming growth factor ; VEGF, vascular endothelial growth factor; EBC, exhaled breath condensate. 
to normal after 3 months of CPAP treatment.

Many factors have been reported to influence the level of TGF- $\beta$ and VEGF. These include age, sex, BMI, smoking history, coexisting systemic diseases, medications and so forth. They may affect oxidative stress which in turn will affect TGF- $\beta$ and VEGF protein concentrations in body. Therefore, subject's age, BMI, smoking status and comorbidities were controlled in our study and partial correlation was used to evaluate the relationship between variables that seem to adjust for these important confounders (31).

We did not really know the reason why AHI in the OSA group is so high whereas the BMI is relatively low for overweight. It is probable that during recruitment our subjects had been selected. Subjects with moderate to severe OSA, i.e., those with $\mathrm{AHI} \geq 20$ events/hour, were recruited in the study. Patients with diabetes mellitus, moderate to severe dyslipidemia, hypertension, and BMI >32 were excluded. These factors such as diabetes mellitus, severe dyslipidemia, hypertension, age, and BMI are confounders of body weight.

The main limitations of our study are the short observation period of 3 months, small sample size, and a lack of histological examination. There are factors that may also have caused reductions on the levels of the CPAP effectors but were not taken into considerations at the time of experiment. For example, patients coming to a sleep clinic could have other impacts on life-style, sleep habits and medications that could alter the levels of these biomolecules. Moreover, confounders were not eliminated or adjusted in our model and it is possible that the observed relationships between OSA and CPAP were driven by confounders and not by CPAP alone. We did not exclude patients with known airway disease which might influence our results. We do not have any data, beyond spirometry, on whether these individuals had airways diseases such as asthma. Our control subjects were recruited from the sleep clinic with AHI of $<5$ who do not have hypersomnolence. The control group in this study were not healthy volunteers and may not ideally represent a healthy control group. The experimental design also suffers from not including a follow-up assessment in the control group. Nevertheless, these results can serve as preliminary evidence from a pilot study for a method of identifying changes in chronic airway inflammation and airway remodeling markers as a result of therapeutic intervention.

\section{Acknowledgments}

We would like to acknowledge the help with statistics from
I-Shiang Tzeng, PhD. Department of Research, Taipei Tzu Chi Hospital, Buddhist Tzu Chi Medical Foundation, New Taipei City.

Funding This work was supported by a grant from the Ministry of Science and Technology (Grant MOST 105-2314-B-303-016-MY3).

\section{Footnote}

Conflicts of Interest: The authors have no conflicts of interest to declare.

Ethical Statement: The authors are accountable for all aspects of the work in ensuring that questions related to the accuracy or integrity of any part of the work are appropriately investigated and resolved. All procedures performed in studies involving human participants were in accordance with the ethical standards of the institutional and/or national research committee (approval number: 04-XD39-106) and with the 1964 Helsinki declaration and its later amendments or comparable ethical standards. All patients gave written informed consent to participated in the study.

Open Access Statement: This is an Open Access article distributed in accordance with the Creative Commons Attribution-NonCommercial-NoDerivs 4.0 International License (CC BY-NC-ND 4.0), which permits the noncommercial replication and distribution of the article with the strict proviso that no changes or edits are made and the original work is properly cited (including links to both the formal publication through the relevant DOI and the license). See: https://creativecommons.org/licenses/by-nc-nd/4.0/.

\section{References}

1. Lavie L. Obstructive sleep apnoea syndrome--an oxidative stress disorder. Sleep Med Rev 2003;7:35-51.

2. Kharitonov SA, Barnes PJ. Exhaled markers of pulmonary disease. Am J Respir Crit Care Med 2001;163:1693-722.

3. Paulsen FP, Steven P, Tsokos M, et al. Upper airway epithelial structural changes in obstructive sleep-disordered breathing. Am J Respir Crit Care Med 2002;166:501-9.

4. Kimoff RJ, Hamid Q, Divangahi M, et al. Increased upper airway cytokines and oxidative stress in severe obstructive sleep apnoea. Eur Respir J 2011;38:89-97.

5. Desai P, Yang J, Tian B, et al. Mixed-effects model of epithelial-mesenchymal transition reveals rewiring of signaling networks. Cell Signal 2015;27:1413-25. 
6. Yang ZC, Yi MJ, Ran N, et al. Transforming growth factor- $\beta 1$ induces bronchial epithelial cells to mesenchymal transition by activating the Snail pathway and promotes airway remodeling in asthma. Mol Med Rep 2013;8:1663-8.

7. Ji X, Li J, Xu L, et al. IL4 and IL-17A provide a Th2/ Th17-polarized inflammatory milieu in favor of TGF- $\beta 1$ to induce bronchial epithelial-mesenchymal transition (EMT). Int J Clin Exp Pathol 2013;6:1481-92.

8. Bakakos P, Patentalakis G, Papi A. Vascular biomarkers in asthma and COPD. Curr Top Med Chem 2016;16:1599-609.

9. Meyer N, Akdis CA. Vascular endothelial growth factor as a key inducer of angiogenesis in the asthmatic airways. Curr Allergy Asthma Rep 2013;13:1-9.

10. Moon IJ, Kim DY, Rhee CS, et al. Role of angiogenic factors in airway remodeling in an allergic rhinitis murine model. Allergy Asthma Immunol Res 2012;4:37-45.

11. Jászai J, Schmidt MHH. Trends and challenges in tumor antiangiogenic therapies. Cells 2019. doi: 10.3390/cells8091102.

12. Marin JM, Carrizo SJ, Vicente E, et al. Long-term cardiovascular outcomes in men with obstructive sleep apnoea-hypopnoea with or without treatment with continuous positive airway pressure: an observational study. Lancet 2005;365:1046-53.

13. Iber C, Ancoli-Israel S, Chesson AL, et al. The AASM manual for the scoring of sleep and associated events: rules, terminology, and technical specifications. Westchester: American Academy of Sleep Medicine, 2007.

14. Johns MW. A new method for measuring daytime sleepiness: the Epworth sleepiness scale. Sleep 1991;14:540-5.

15. Stradling JR, Schwarz EI, Schlatzer C, et al. Biomarkers of oxidative stress following continuous positive airway pressure withdrawal: data from two randomised trials. Eur Respir J 2015;46:1065-71.

16. Turnbull CD, Akoumianakis I, Antoniades C, et al. Overnight urinary isoprostanes as a marker of oxidative stress in obstructive sleep apnoea. Eur Respir J 2017. doi: 10.1183/13993003.01787-2016.

17. Maeder MT, Strobel W, Christ M, et al. Comprehensive biomarker profiling in patients with obstructive sleep apnea. Clin Biochem 2015;48:340-6.

18. Peled N, Shitrit D, Bendayan D, et al. Association of elevated levels of vascular endothelial growth factor in obstructive sleep apnea syndrome with patient age rather than with obstructive sleep apnea syndrome severity. Respiration 2007;74:50-5.

19. Steffanina A, Proietti L, Antonaglia C, et al. The plasminogen system and transforming growth factor- $\beta$ in subjects with obstructive sleep apnea syndrome: effects of
CPAP treatment. Respir Care 2015;60:1643-51.

20. Ye J, Liu H, Zhang G, et al. The treg/th17 imbalance in patients with obstructive sleep apnoea syndrome. Mediators Inflamm 2012;2012:815308.

21. Ciftci TU, Kokturk O, Demirtas S, et al. Consequences of hypoxia-reoxygenation phenomena in patients with obstructive sleep apnea syndrome. Ann Saudi Med 2011;31:14-8.

22. Tual-Chalot S, Gagnadoux F, Trzepizur W, et al. Circulating microparticles from obstructive sleep apnea syndrome patients induce endothelin-mediated angiogenesis. Biochim Biophys Acta 2014;1842:202-7.

23. Carpagnano GE, Spanevello A, Sabato R, et al. Exhaled $\mathrm{pH}$, exhaled nitric oxide, and induced sputum cellularity in obese patients with obstructive sleep apnea syndrome. Transl Res 2008;151:45-50.

24. Carpagnano GE, Spanevello A, Sabato R, et al. Systemic and airway inflammation in sleep apnea and obesity: the role of ICAM-1 and IL-8. Transl Res 2010;155:35-43.

25. Sariman N, Levent E, Aksungar FB, et al. Homocysteine levels and echocardiographic findings in obstructive sleep apnea syndrome. Respiration 2010;79:38-45.

26. Greulich T, Hattesohl A, Grabisch A, et al. Detection of obstructive sleep apnoea by an electronic nose. Eur Respir J 2013;42:145-55.

27. Ding X, Yu C, Liu Y, et al. Chronic obstructive sleep apnea accelerates pulmonary remodeling via TGF- $\beta / \mathrm{miR}-185 / \mathrm{CoLA} 1$ signaling in a canine model. Oncotarget 2016;7:57545-55.

28. Ding WX, Dong YB, Ding N, et al. Adiponectin protects rat heart from left ventricular remodeling induced by chronic intermittent hypoxia via inhibition of TGF- $\beta$ / smad2/3 pathway. J Thorac Dis 2014;6:1278-84.

29. Wåhlin-Larsson B, Ulfberg J, Aulin KP, et al. The expression of vascular endothelial growth factor in skeletal muscle of patients with sleep disorders. Muscle Nerve 2009;40:556-61.

30. Schwarz EI, Martinez-Lozano Sinues P, Bregy L, et al. Effects of CPAP therapy withdrawal on exhaled breath pattern in obstructive sleep apnoea. Thorax 2016;71:110-7.

31. Porreca E, Di Febbo C, Vitacolonna E, et al. Transforming growth factor-beta1 levels in hypertensive patients: association with body mass index and leptin. Am J Hypertens 2002;15:759-65.

Cite this article as: Lin CC, Liaw SF, Chiu CH, Lin MW. Effects of continuous positive airway pressure on exhaled transforming growth factor- $\beta$ and vascular endothelial growth factor in patients with obstructive sleep apnea. J Thorac Dis 2020;12(3):932-941. doi: 10.21037/jtd.2019.12.55 